\title{
Preparation of Magnesium Phosphate Cement and Application in Concrete Repair
}

\author{
Sainan Xing ${ }^{1}$, and Chengyou $\mathrm{Wu}^{1 *}$ \\ ${ }^{1}$ School of Civil Engineering, Qinghai University, 810016, Xining, China
}

\begin{abstract}
Potassium magnesium phosphate cement (MKPC) was prepared by using magnesium oxide $(\mathrm{MgO})$ and potassium dihydrogen phosphate (KH2PO4, KDP). The effects of different calcination temperature, water-cement ratio and ratio on the operation of magnesium phosphate cement were studied. The effects of different water - cement ratio and ratio on the bonding strength of potassium magnesium phosphate cement and the application of potassium phosphate and magnesium cement in concrete repair and reinforcement were determined by experiments such as bending resistance, splitting, compression and bearing capacity. The experimental results show that the calcination temperature is $1100{ }^{\circ} \mathrm{C}$, the calcination time is $1 \mathrm{~h}$, the settling time of magnesium oxide is $39 \mathrm{~min}$, and the compressive strength of one day reaches $53 \mathrm{MPa}$. The water - cement ratio with the best bonding strength is 0.2 , the mass ratio is $2: 1$.To meet the rapid repair of the construction requirements, is expected to be applied to the actual repair works.
\end{abstract}

\section{Introduction}

With the development of economy, people continue to improve the quality of life, and they have a higher requirement for travel quality. However, with the increasing number of road work, the load on the road is also growing. It means that appearance of pavement maintenance problems. Currently, the road in our country take cement concrete mainly, but the traditional maintenance method is generally the first to remove the damaged part, and then re-pouring, this method is not only time-consuming, and concrete to take longer maintenance time. At present, we know a kind of adhesive repair material is epoxy resin, but its functionalization research focus on experimental research. Due to its time-consuming, consumables, power consumption and type single and other disadvantages, so the test results are unpredictable. Meanwhile, epoxy resin achieve different functional applications often need to add functional filler, which hazardous to health and pollution of the environment. So it is necessary to study new materials that both to protect the environment, but also effective repair [1].

Magnesium phosphate cement prepared with lithium magnesium slag (MKPC) is a re-use of lithium waste and non-toxic, which is a new type of inorganic cementitious material with high bonding strength with old concrete. MKPC has the characteristics of early strength, fast hard, so that it can meet the requirements of rapid repair. MKPC saves

* Corresponding author: wuchengyou86@163.com 
energy and protects environment as a new type of fast repair materials, can be widely used in roads, bridges, airport runways, which has attracted more and more attention from academics and the community[2]. This paper improves the maneuverability and volumetric stability of lithium magnesium slag magnesium phosphate cement by adjusting the calcination temperature and the way of adding fly ash to reduce the cost and obtain a new type of quick repair material which is economical, practical and environmentally friendly, and verify its feasibility in practical engineering.

\section{Experiment}

\subsection{Raw materials.}

The raw materials used in this experiment are by-product magnesium oxide $(\mathrm{MgO})$ in the process of extracting $\mathrm{Li}_{2} \mathrm{CO}_{3}$ from Qinghai CITIC Guoan Technology Co., Ltd. and potassium dihydrogen phosphate $\left(\mathrm{KH}_{2} \mathrm{PO}_{4}\right)$ produced by Hedong District Hongyan Reagent Factory in Tianjin. Table1 is the chemical composition of lithium magnesium slag content. Table 2 is the technical indicators of potassium dihydrogen phosphate.

Table 1. The composition of magnesium hydroxide residue after producing $\mathrm{Li}_{2} \mathrm{CO}_{3}$

\begin{tabular}{ccccccccccc}
\hline Composition & $\mathrm{Mg}^{2+}$ & $\mathrm{B}_{2} \mathrm{O}_{3}$ & $\mathrm{Ca}^{+}$ & $\mathrm{K}^{+}$ & $\mathrm{Na}^{+}$ & $\mathrm{Cl}^{-}$ & $\mathrm{SO}_{4}^{2-}$ & $\mathrm{Li}^{+}$ & LOI* $^{*}$ & Total \\
\hline $\begin{array}{c}\text { Mass fraction } \\
/ \%\end{array}$ & 59.22 & 4.91 & 0.33 & 0.027 & 0.36 & 0.92 & 0.45 & 0.25 & 32.55 & 99.02 \\
\hline
\end{tabular}

Table 2. $\mathrm{KH}_{2} \mathrm{PO}_{4}$ technical indicators

\begin{tabular}{ccccc}
\hline $\begin{array}{c}\text { Chemical } \\
\text { composition }\end{array}$ & $\mathrm{KH}_{2} \mathrm{PO}_{4}$ & $\mathrm{SO}^{2-}$ & $\mathrm{As}$ & $\mathrm{Fe}$ \\
\hline Percentage $\%$ & 99.5 & 0.003 & 0.005 & 0.001 \\
\hline
\end{tabular}

\subsection{Experimental method.}

The cement sample was manufactured in the case where $\mathrm{KH}_{2} \mathrm{PO}_{4}$ and $\mathrm{MgO}$ mass ratio and water-cement ratio unchanged. $\mathrm{KH}_{2} \mathrm{PO}_{4}$ and $\mathrm{MgO}$ in turn into the mortar, first dry mixing $2 \mathrm{~min}$, then added water at low speed stirring $1 \mathrm{~min}$, high-speed stirring $30 \mathrm{~s}$, and the stirred mixture was quickly poured into an iron mold of $10 \mathrm{~mm} \times 10 \mathrm{~mm} \times 10 \mathrm{~mm}$, and shook it, and the specimen was placed at room temperature curing after demoulding. The strength of samples was tested at different ages[3]. The determination of the activity of magnesium oxide is shown in Ref4 [4].

\section{Results and analysis}

\subsection{Effect of calcination temperature and time of lithium magnesium slag on MKPC.}

As the magnesium oxide content is low and the condensation of magnesium phosphate cement coagulation is fast, it is necessary to carry out calcination treatment of lithium magnesium slag, the optimum temperature for calcination is determined by the activity of magnesium oxide and the compressive strength of the samples.

Table 3 shows that with the increase of calcination temperature and the prolongation of calcination time, the setting time and compressive strength of MKPC increases gradually. 
But taking into account the nature of engineering applications, condensation time too fast causes the actual can't operate. Meanwhile, the initial setting time can't be too slow. To meet the requirements of engineering construction, choosing the calcination temperature $\left(1100^{\circ} \mathrm{C}\right)$ and calcination time $(1 \mathrm{~h})$.

Table 3. Compressive strength of MKPC specimen/MPa

\begin{tabular}{clcccc}
\hline $\begin{array}{l}\text { Calcination temperature } \\
\text { and time }\end{array}$ & $1 \mathrm{~h}$ & $1 \mathrm{~d}$ & $3 \mathrm{~d}$ & $7 \mathrm{~d}$ & Setting time / min \\
\hline $800^{\circ} \mathrm{C} 3 \mathrm{~h}$ & 19.6 & 30.4 & 47.2 & 51.0 & 5 \\
$900^{\circ} \mathrm{C} 1 \mathrm{~h}$ & 21.1 & 52.3 & 57.4 & 62.2 & 8 \\
$900^{\circ} \mathrm{C} 2 \mathrm{~h}$ & 20.8 & 41.9 & 56.6 & 65.0 & 11 \\
$900^{\circ} \mathrm{C} \mathrm{3h}$ & 19.1 & 48.3 & 62.9 & 64.0 & 12 \\
$1000^{\circ} \mathrm{C} 1 \mathrm{~h}$ & 21.0 & 51.9 & 62.5 & 68.8 & 15 \\
$1000^{\circ} \mathrm{C} 2 \mathrm{~h}$ & 9.4 & 49.6 & 56.6 & 62.8 & 28 \\
$1000^{\circ} \mathrm{C} 3 \mathrm{~h}$ & - & 33.5 & 42.5 & 52.2 & 63 \\
$1100^{\circ} \mathrm{C} 1 \mathrm{~h}$ & 8.0 & 53.4 & 61.0 & 64.5 & 39 \\
$1100^{\circ} \mathrm{C} 2 \mathrm{~h}$ & - & 39.1 & 50.2 & 52.9 & 65 \\
\hline
\end{tabular}

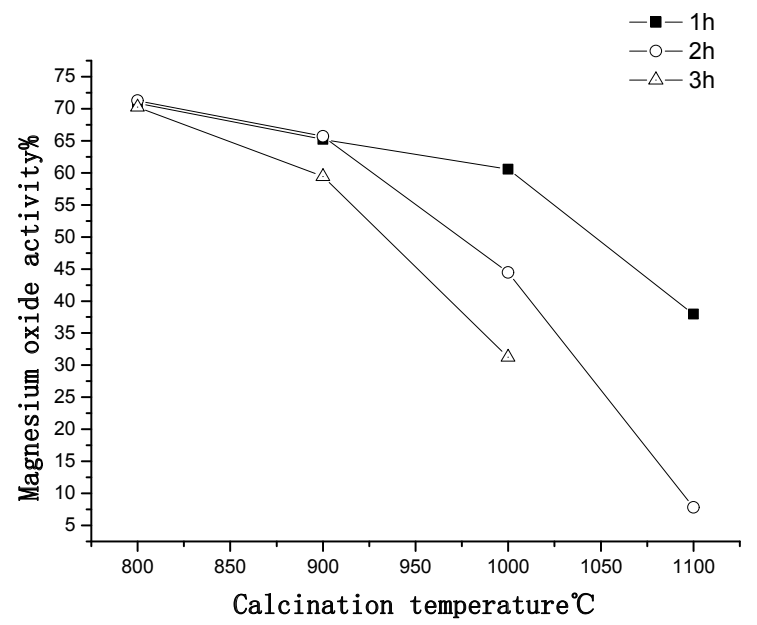

Fig.1. Relationship between the activity of magnesium oxide and the calcination temperature

Fig.1 displays that with the increase of calcination temperature, the activity of magnesium oxide decreases gradually in the case of the same calcination time. At the same calcination temperature, the activity of magnesium oxide decreases with the increase of calcination time. It means that the MKPC will enhance the operability in the later stage. It is necessary to further verify the accuracy of the effect of calcination temperature on the activity of magnesium oxide by staining test.

The principle of staining test [5] is acid -base neutralization. Take the citric acid solution $50 \mathrm{~g}$ (11\%concentration) in the beaker (including rotor), then add two drops of phenolphthalein indicator. Placing it in a discoloration tester, then add $15 \mathrm{~g}$ magnesium oxide powder. Discoloration time is from adding powder to discoloration of solution. 


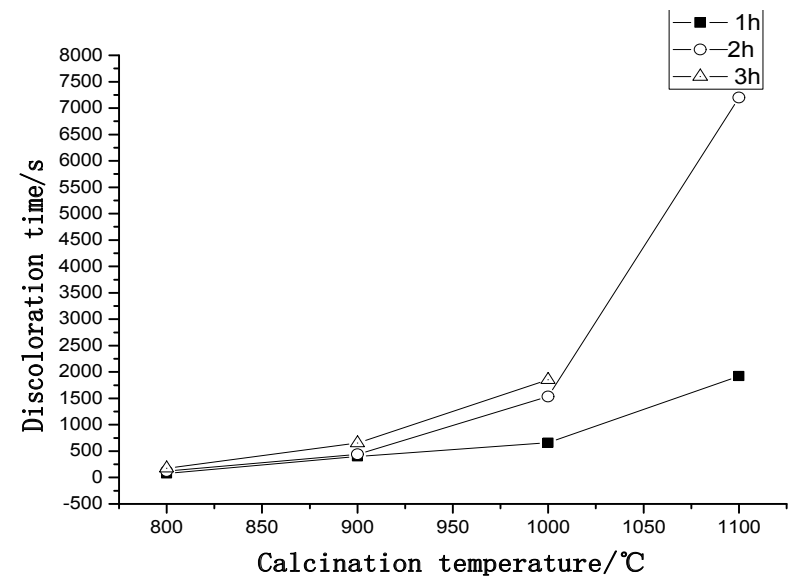

Fig. 2. Relationship between calcination temperature and discoloration time of $\mathrm{MgO}$

Fig.2 implies that the activity of magnesium oxide decreases with increase of calcination temperature and calcination time. It also proves the accuracy of the test.

\subsection{Influence of concrete strength ratio and water cement ratio on MKPC.}

\subsubsection{Plain concrete strength ratio.}

When the water cement ratio was 0.2 , the mass ratio of magnesium oxide and potassium dihydrogen phosphate is $1: 1$. The mass ratio of magnesium oxide and potassium dihydrogen phosphate was $1: 1,2: 1,2.5: 1$ and $3: 1$ respectively. The stirred mixture was quickly pasted onto the fracture surface of the concrete piece. Tested the flexural strength of $3 \mathrm{~h}, 1 \mathrm{~d}, 7 \mathrm{~d}$.

Table 4. Effect of MKPC mass ratio on bond strength/Mpa

(Temperature $1100^{\circ} \mathrm{C}$ Insulation $1 \mathrm{~h} \mathrm{~W} / \mathrm{C} 0.2$ )

\begin{tabular}{cccc}
\hline Mass ratio & $3 \mathrm{~h}$ & $1 \mathrm{~d}$ & $7 \mathrm{~d}$ \\
\hline $1: 1$ & 4.59 & 2.67 & 4.70 \\
$2: 1$ & 5.01 & 5.30 & 7.11 \\
$2.5: 1$ & 4.90 & 6.01 & 5.22 \\
$3: 1$ & 3.93 & - & - \\
\hline
\end{tabular}

Table 4 demonstrates that In the case where the water-cement ratio is kept constant, the best mass ratio of the adhesive strength is $2: 1$, water-cement ratio of 0.2 , the mass ratio of 2:1 magnesium phosphate cement (MKPC) paste the concrete rupture surface, the $7 \mathrm{~d}$ flexural strength up to $7.11 \mathrm{MPa}$, which indicates that MKPC has a strong paste repair performance.

\subsubsection{Water cement ratio.}

The mass ratio of magnesium oxide to potassium dihydrogen phosphate is $2: 1$, and the ratio of water to cement is respectively $0.16,0.2,0.25$ and 0.3 . The stirred mixture was quickly pasted onto the fracture surface of the concrete piece. Tested the flexural strength of $3 \mathrm{~h}, 1 \mathrm{~d}$, $7 \mathrm{~d}$. 
Table 5. Impact of water cement ratio on $\mathrm{MKPC} / \mathrm{Mpa}$

(Calcination temperature $1100^{\circ} \mathrm{C}$ insulation $1 \mathrm{~h}$ ratio $2: 1$ )

\begin{tabular}{cccc}
\hline W/C & $3 \mathrm{~h}$ & $1 \mathrm{~d}$ & $7 \mathrm{~d}$ \\
\hline 0.16 & & Too dry that on operate & \\
0.2 & 5.01 & 6.30 & 7.11 \\
0.25 & 4.06 & 6.32 & 5.71 \\
0.3 & 3.89 & 4.19 & 4.56 \\
\hline
\end{tabular}

The experimental data shows that it is so dry that can't be pasted when the water-cement ratio is 0.16 , the MKPC has the best paste strength while ratio of $2: 1$ and water-cement ratio of 0.2 , because its flexural strength of $7 \mathrm{~d}$ can reach $7.1 \mathrm{MPa}$. When the ratio of water to cement is greater than 0.2 , the flexural strength of MKPC bonded concrete specimen decreases with the increase of water-cement ratio, The reason for this phenomenon is that increase of water-cement ratio cause MKPC shrinkage, and lower bond strength[6].

\subsection{Impact of splitting repair experiment on MKPC.}

The split $100 \mathrm{~mm} \times 100 \mathrm{~mm} \times 100 \mathrm{~mm}$ concrete test piece was bonded with water ratio of 0.2 , mass ratio of $2: 1$ and fly ash parameters of $30 \%$ of the MKPC slurry. Placed at room temperature for curing, testing $3 \mathrm{~h}, 1 \mathrm{~d}, 7 \mathrm{~d}$ splitting tensile strength [7]. The experimental results were $11.67 \mathrm{KN}, 18.51 \mathrm{KN}, 21.38 \mathrm{KN}$ respectively, compared with the original splitting tensile bearing capacity, the bearing capacity were restored to the original value of $36.53 \%, 57.93 \%$ and $66.92 \%$. It is indicated that MKPC does have a strong ability to paste, and the bonding speed with the concrete quickly.

\section{Conclusions}

(1) There is an economical and environmentally friendly method that utilizing industrial waste residue to prepare magnesium phosphate cement. The production process of MKPC was studied. It was found by experiment that magnesium phosphate cement was prepared with lithium magnesium slag to have the calcination temperature of $1100^{\circ} \mathrm{C}$.

(2) In order to apply it to the actual work of repairing concrete, the mass ratio of magnesium oxide to potassium dihydrogen phosphate should be $2: 1$, the water-cement ratio is 0.2 .

(3) In the application of potassium phosphate and magnesium cement engineering, it is found that potassium phosphate magnesium cement has a strong bonding capacity, fast hard, early strength through the bending, split and the others is a good choice for quick repair works.

(4) The preparation of magnesium phosphate cement in lithium magnesium slag, is a kind of environmentally friendly and economical magnesium phosphate cement preparation method, although there are still many problems can't be resolved, it will be more research and exploration on this project. In the future life of lithium magnesium slag prepared by potassium magnesium phosphate cement (new inorganic cementitious materials) can be widely used in roads, bridges, airport runways and other repair works.

This study was supported by the National Natural Science Foundations of China (grants No.51662035, 
No.U1407104, No.51678304 and No.21401209), Natural Science Foundations of Qinghai Province (grants No.2015-ZJ-947Q and 2015-ZJ-937Q) and foundation teaching and research innovation team project of higher education institution of Qinghai province.

\section{References}

1. Z Ruan, Z H Liu, Z P Deng, S Y Cheng, S T Ye. Research Progress in Functionalization of Epoxy Resin Systems. J. 12,8 (2015)

2. L R Wu. Study on Modification of Magnesium Phosphate Cement by Fly Ash and Its Engineering Application. J. (2014).

3. Y S Tan, H F Yu, Y Li, J M Dong, et al. Preparation of Fly Ash Magnesium Phosphate Cement Using Byproduct Magnesium Oxide Containing Boron from Salt Lake. J. 42, 8 (2014).

4. J M Dong, H F Yu, L M Zhang. Study on Experimental Conditions of Hydration Methods of Determining Active Magnesium Oxide Content. J. 18 , 4 (2010).

5. J P Yuan, C Wang, K Y Shen, D L Xiao. Commentary on Anti Tarnishing Experiment and Evaluation Method of Silver Alloy. J. 8, 4 (2006).

6. Q B Yang, B Y Lei. Effect of Fly Ash on Adhesive Properties of Phosphate Cement Mortar and Concrete. J. 3 (2016).

7. W H Chen, S S Cui. Flexural Behavior of Prestressed Concrete Beams Strengthened with CFRP Sheets Bonded with Inorganic Adhesive. J. 36, 5(2014). 